\title{
VINDICACIÓN DE LAS ESFERAS PÚBLICAS: ESPACIOS DE CRÍTICA PARA TIEMPOS CRÍTICOS ${ }^{1}$
}

\author{
JOSÉ MARÍA MUÑOZ TERRÓN \\ Universidad de Almería
}

\begin{abstract}
RESUMEN: El artículo replantea, en confrontación con Reinhart Koselleck, la relación entre tiempos de crisis y esferas públicas, así como la «dialéctica», ahí implicada, entre «secreto» y «publicidad». Desde este marco interpreto la crisis contemporánea de modelos de comunicación y participación políticas, en parte por el impacto de las TIC, con referencia a fenómenos sociopolíticos recientes en España, como el movimiento $15 \mathrm{M}$ o el nuevo partido Podemos. La crítica genera o agudiza las crisis y éstas se expresan en aquella. El ideal de la esfera pública se reconfigura con cada crisis, para confrontar a sociedad y política con el nivel de crisis su tiempo. Frente a Koselleck, reitero la exigencia normativa de esferas públicas como espacios críticos, ámbitos sociales, intermedios entre política y mundo de la vida.
\end{abstract}

PALABRAS CLAVE: esfera pública; crítica; crisis; tecnologías de la información y la comunicación (TIC); sociedad civil; secreto.

\section{Vindication of public spheres: critique spaces for critical times}

ABSTRACT: In opposition to Reinhart Koselleck, the article raises again the relationship between times of crisis and public spheres and also the related "dialectics» of «secrecy» and «publicity». From this premise I interpret the contemporary crisis of models of political communication and participation, partly because of the impact of ITCs, alluding to recent socio-political phenomena in Spain, such as the $15 \mathrm{M}$ movement or Podemos party. The critique generates or sharpens crisis, and crisis expresse themselves in critique. The ideals of public sphere are reformulated on their own way with every crisis, to confront each society with the level of crisis of the times. In contrast to Koselleck, I reaffirme the normative requirement of public spheres as critical spaces, social realms, somewhere between politics and life-world.

KEY WORDS: public sphere; critique; crisis; information and communication technologies (ITCs); civil society; secrecy.

\section{CRÍTICA, CRISIS Y ESFERA PÚBLICA}

«Vamos a inundar con nuestra curiosidad y nuestro entusiasmo los últimos rincones de España; vamos a ver España y a sembrarla de amor y de indignación.»

1 Este trabajo recoge resultados de la investigación realizada en el Instituto de Filosofía de la Universidad Humboldt de Berlín (Alemania), gracias a una Beca para Estancias de movilidad en el extranjero «José Castillejo» para jóvenes doctores (CAS14/00398) del Ministerio de Educación, Cultura y Deporte. Asimismo se inscribe en el Proyecto I+D+i Cultura cívica on line: Teoría y medida, Código CSO2009-13396. Agradezco a mis compañeros Cayetano J. Aranda Torres y Antonio J. Carrillo Burgos su constante apoyo. A M ${ }^{\mathrm{a}}$ Teresa Martín Palomo y revisores anónimos, su lectura del manuscrito. 
Quien así clama no es un joven orador espontáneo en una de las plazas tomadas en diversas ciudades españolas por el movimiento 15M en las primaveras de 2011 y 2012 .

Vamos a tender una red de nudos de esfuerzo por todos los ámbitos españoles, red que a la vez será órgano de propaganda y órgano de estudio del hecho nacional; red, en fin, que forme un sistema nervioso por el que corran vitales oleadas de sensibilidad y automáticas, poderosas corrientes de protesta.

No se trata de un panfleto popular ni de un llamamiento cibernético a la revuelta organizada; ni de un manifiesto de la Spanish Revolution. Son palabras pronunciadas por "un individuo", como él mismo dice, "en medio del camino de su vida» que, en una conferencia de afortunado título, presenta una asociación de intelectuales recién creada, cuyo objetivo declarado, junto a la investigación y la propuesta de soluciones para los problemas seculares de su patria, es: «defender, por medio de una crítica atenta y sin compromisos, cuanto va surgiendo en nuestro país con caracteres de aspirante vitalidad contra las asechanzas que mueven en derredor todas las cosas muertas o moribundas ${ }^{2}$. Ya al comienzo mismo del discurso había afirmado: «En épocas críticas puede una generación condenarse a histórica esterilidad por no haber tenido el valor de licenciar las palabras recibidas, los credos agónicos, y hacer en su lugar la enérgica afirmación de sus propios, nuevos sentimientos ${ }^{3}$. Con el tono de un imperativo histórico, proclama este testimonio con más de un siglo de actualidad, el vínculo entre el ejercicio de la crítica política en los espacios públicos y los tiempos de crisis. El presente artículo analiza la compleja relación entre las épocas críticas y las esferas públicas como espacios sociales de la crítica, mediante una discusión de las tesis de Reinhart Koselleck en su obra Crítica y crisis $^{4}$, con el objetivo de reafirmar

2 El «Prospecto de la "Liga de Educación Política Española"», redactado por José Ortega y Gasset, aparece impreso en el otoño de 1913 con la firma de destacadas personalidades como Azaña o Fernando de los Ríos (cfr. Ortega y Gasset, J., Obras completas. Tomo I (19021915), Madrid, Santillana y Fundación José Ortega y Gasset, 2004, pp. 738-744. La conferencia «Vieja y nueva política» tiene lugar en Madrid, en el Teatro de la Comedia, el 23 de marzo de 1914. (Ibíd., pp. 707-737). Ver también: Ibíd., Notas a la edición, pp. 941, 985-988. Las citas supra corresponden a: Ibíd., pp. 725, 738.

3 ORTEGa, o.c., pp. 711-712.

4 En el Prefacio a la $1^{\text {a }}$ edición (Koselleck, R., Kritik und Krise. Eine Studie zur Pathogenese der bürgerlichen Welt, Freiburg i. B./München, Karl Alber Verlag, 1959), el autor remite como origen de la obra a su tesis doctoral aprobada en la Universidad de Heidelberg en 1954. A partir la $3^{\text {a }}$ edición (Frankfurt a. M., Suhrkamp, 1973), la obra se reedita y reimprime, con las leves modificaciones de la $2^{a}$ edición (1969), siempre con idéntica paginación de la primera. En castellano se publica una muy temprana traducción (Crítica y crisis del mundo burgués, trad. de Rafael de la Vega, Madrid-México-Pamplona, Rialp, 1965) de la que disponemos hoy en una versión revisada (Crítica y crisis. Un estudio sobre la patogénesis del mundo burgués, ed. y nota preliminar de J. A. Pardos, revisión de la trad.: J. A. Pardos y J. Pérez de Tudela, Madrid, Trotta / Universidad Autónoma de Madrid, 2007, pp. 19-238). Esta nueva edición española incluye, como valioso apéndice, la versión en castellano del trabajo de Koselleck sobre el concepto de crisis: «Krise», en: BRUnNer, O., Conze, W. y Koselleck, R. (eds.), Geschichtliche Grundbegriffe: Historisches Lexikon zur politisch-sozialen Sprache in Deutschland. Stuttgart, Ernst Klett Verlag. Vol. III, pp. 617-650; 
la publicidad como un principio de la política que debe tomar cuerpo, también en la actual cultura digital, en las esferas públicas como ámbitos sociales de discusión y cuestionamiento. Se parte para ello de (1) una contextualización de las tesis koselleckianas en el marco de la discusión en torno al concepto de esfera pública, en la segunda mitad del siglo XX en Alemania, desde la que se amplía la perspectiva a la actualidad para justificar la oportunidad de una lectura polémica de Crítica y crisis aplicada al análisis de fenómenos sociales y políticos de hoy. Tras un breve repaso de las raíces comunes de «crítica» y «crisis», que pone de relieve la importancia política de la relación entre ambos conceptos (2), se expone luego (3) la conexión entre los diferentes significados de "público», desde la distinción público/privado, $y$ la caracterización de las esferas públicas como ámbitos sociales de ejercicio de crítica de la política. Se lleva a cabo después (4) una presentación sintética del argumento koselleckiano sobre el vínculo entre tiempos y espacios críticos, así como entre esta relación "crítica-crisis» y la "dialéctica» secretopublicidad, dinámicas introducidas por la crítica ilustrada del Estado absolutista. Seguidamente se expone (5) una defensa, frente a Koselleck, de la validez normativa de las esferas públicas como espacios sociales de crítica política, con una discusión de su posible aplicación para interpretar algunos acontecimientos socio-políticos recientes. Por último, (6) las conclusiones reafirman la necesidad de espacios críticos para una constante reinvención de la política en, y más allá de, los tiempos críticos.

\section{Contextualización de una tesis disputada: la sombra de Carl Schmitt es alargada}

La relación entre crítica y crisis que plantea la obra de Reinhart Koselleck tiene su inmediato contexto histórico-filosófico en el debate sobre el concepto de esfera pública entablado a partir de los años cincuenta del siglo XX en la filosofía, la historia y la teoría social y política en Alemania. La discusión adquiere tintes especialmente combativos en el clima de fuerte disputa ideológica y política de posguerra, marcado por la influencia de C. Schmitt. Con este mantiene Koselleck una estrecha relación discipular, que se refleja en una determinada visión de la relación entre moral y política sobre la que, en buena parte, se levantan las tesis de Crítica y crisis 5 . En una clave similar publica Hanno Kesting, también en 1959, su Filosofía de la historia y guerra civil mundial ${ }^{6}$. Como apuntaba en la época una reseña conjunta de las dos obras, ambos autores «conciben la crisis mundial contemporánea como la extensión a todo el globo terráqueo, de la crisis desencadenada con la Revolución Francesa, de

«Crisis», trad. de J. Pérez de Tudela, en: Koselleck, R., Crítica y crisis. o. c., pp. 239-281. En lo que sigue, las obras se citarán con preferencia por las ediciones originales y, salvo indicación contraria expresa, en traducción propia o revisada, atendiendo en todo caso, cuando existen, a las correspondientes versiones castellanas.

5 Menring, Reinhard, Carl Schmitt zur Einführung, Hamburg, Junius Verlag, 2011, pp. 128,177 .

6 Kesting, H. Geschichtsphilosophie und Weltbürgerkrieg. Deutungen der Geschichte von der Französischen Revolution bis zum Ost-West-Konflikt, Heidelberg: Carl Winter, Universitätsverlag, 1959. 
una guerra civil europea ${ }^{7}$. En este mismo contexto de disputa de la segunda mitad de los cincuenta, ya se había dado a conocer en alemán La sociedad abierta y sus enemigos, obra de Karl R. Popper cuya primera edición original en inglés databa de $1945^{8}$ y que puede ser leída como un extenso alegato a favor de la publicidad, en tanto apertura, libertad ilimitada de comunicación, como condición básica de todo orden político9 . A principios de los sesenta, Helmuth Plessner defiende también una esfera pública «desmitificada», como espacio de responsabilidad y garantía de la libertad social, frente a concepciones marxistas y existencialistas que «devalúan» la publicidad desde el concepto de alienación ${ }^{10}$. En 1966, vuelve Hanno Kesting sobre sus tesis con una teoría de la opinión pública, a la que, «en tanto opinión publicada», tacha de propaganda ${ }^{11}$. A fines de los setenta son los trabajos de Lucian Hölscher los que desarrollan polémicamente la compleja relación constitutiva entre el secreto y la esfera pública moderna con su pretensión de crítica universal ${ }^{12}$. Hoy, frente a los desafíos de la digitalización de la sociedad y la política, hay también quienes, como Byung-Chul Han, vuelven a invocar a Carl Schmitt y aquel marco de discusión ${ }^{13}$.

Publicada originalmente en 1962, la conocida obra habermasiana sobre el Cambio estructural de la esfera pública ${ }^{14}$, se inscribe de lleno igualmente en esa misma

7 Habermas, J., «Verrufener Fortschritt - verkanntes Jahrhundert. Zur Kritik an der Geschichtsphilosophie», en: Merkur. Deutsche Zeitschrift für europäisches Denken. XIV (1), 1960, pp. 468-477. Se cita: p. 469. La reseña se reeditará con algunos leves pero significativos cambios en: íd., "Zur Kritik an der Geschichtsphilosophie», en: Philosophish-politische Profile. Frankfurt a. M., Suhrkamp, 1981, pp. 435-444.

8 Popper, Karl R., The Open Society and Its Enemies, Vol. I. The Spell of Plato; Vol. II. The High Tide of Profecy: Hegel, Marx and the Aftermath, Routledge \& Kegan Paul Ltd., London, 1957. [ $3^{\text {a }}$ edición, revisada]. La traducción alemana de los dos volúmenes, realizada por Paul K. Feyerabend, aparece en Suiza, con una dedicatoria, una introducción y discurso dedicados a la memoria de I. Kant, como «filósofo de la libertad y la humanidad», en el 150 aniversario de su muerte: PoPPER, KARL R., Der Zauber Platons. Die offene Gesellschaft und ihre Feinde, I, Bern, Franke Verlag, 1957; íd., Falsche Propheten. Hegel, Marx und die Folgen. Die offene Gesellschaft und ihre Feinde, II, Bern, Franke Verlag, 1958.

9 Cfr. Gerhardt, V., Öffentlichkeit. Die politische Form des Bewusstseins, München, Verlag C. H. Beck, 2012, pp. 219-223; GERHARDT, V., Licht und Schatten der Öffentlichkeit. Vorausetzungen und Folgen der digitalen Innovation. Viena: Picus Verlag, 2014, pp. 42-46.

10 Plessner, H., «Das Problem der Öffentlichkeit und die Idee der Entfremdung (1960)», en: íd. Gesammelte Schriften. Vol. X. Schriften zur Sociologie und Sozialphilosophie, Frankfurt a. M., Suhrkamp, 1985, pp. 212-226. Se cita p. 225.

11 Kesting, H., Öffentlichkeit und Propaganda: Zur Theorie der öffentlichen Meinung, Bruchsal, San Casciano Verlag, 1995. Es la reedición de su Habilitationschrift, Aachen, Tech. Hochschul. 1966. Se cita p. 92.

12 Cfr. Hölscher, L., «Öffentlichkeit», en: Brunner, O. et al. (eds.), Geschichtliche Grundbegriffe. Historisches Lexikon zur politisch sozialen Sprache in Deutschland. Vol. 4, Stuttgart, Klett-Cotta, 1978, pp. 413-467; íd., Öffentlichkeit und Geheimnis. Eine begriffsgeschichtliche Untersuchung zur Entstehung der Öffentlichkeit in der frühen Neuzeit, Stuttgart, Klett-Cotta, 1979.

13 Han, B., Transparenzgesellschaft, Berlin, Matthes \& Seitz, 2012; íd., Digitale Rationalität und das Ende des kommunikativen Handelns, Berlin, Matthes \& Seitz, 2013a; íd., Im Schwarm. Ansichten des Digitalen, Berlin, Matthes \& Seitz, 2013b.

14 Se citará por la reedición de la obra publicada a comienzos de los noventa, sin ninguna novedad respecto a 1962, excepto un nuevo prólogo del autor, explicativo de los cambios que 
controversia. Hay en ella continuidades y rupturas con respecto a Koselleck, ${ }^{15}$ lo que conectaría con la discutida proximidad conceptual de destacados francfortianos con respecto a Schmitt ${ }^{16}$. Adorno, Horkheimer y el propio Habermas pretendieron transformar la tesis schmittiana de la fusión sociedad civil-Estado en una «crítica del Estado autoritario ${ }^{17}$. Aunque Habermas ya identificaba el ideal normativo de esfera pública de la modernidad con los procesos de diferenciación entre Estado y sociedad civil, sin embargo, a las alturas de 1962, su paradójica aceptación de que ese modelo se mantendría en una situación de Estado y sociedad indiferenciados le lleva a no ver cuán incompatible sería esto con el concepto moderno de esfera pública crítica y pluralista ${ }^{18}$. En lo que respecta al autor de la Teoría de la acción comunicativa, este debate ${ }^{19}$ podría darse por concluido afirmando con Reinhard Mehring que, como otros autores de la República Federal que deciden enfrentarse con el pasado inmediato de Alemania, Habermas plantea una crítica de la concepción decisionista de la democracia nacional/ista en Schmitt, frente a la que él propone una noción procedimental, en perspectiva cosmopolita, de inspiración kantiana ${ }^{20}$.

Una adecuada comprensión de toda la discusión exige, pues, atender tanto a este trasfondo del debate sobre la Ilustración planteado por Koselleck desde la concepción schmittiana de la política, como a la réplica desde el concepto opuesto de lo político, basado en la existencia de una esfera pública crítica, libre y abierta. Esta comprensión de la política, basada en el principio de la publicidad, se podría remontar, cuanto menos, a la ejemplar formulación en el discurso de Pericles ante sus conciudadanos de Atenas (431 a.C.), el famoso epitaphios logos que transmite Tucídides, cuando afirmaba que la discusión, no solo no estorba la acción política, sino que constituye la preparación imprescindible de todo actuar sabio ${ }^{21}$. Una

requeriría una nueva reescritura del texto: HaBERMAS, J., Strukturwandel der Öffentlichkeit. Untersuchungen zu einer Kategorie der bürgerlichen Gesellschaft, Frankfurt a. M., Suhrkamp, 1990.

15 Benigno, F., «La clarividencia del primer Koselleck», en: Revista de Libros, II ${ }^{\mathrm{a}}$ Época, $\mathrm{n}^{\circ} 150$ (2009); íd., "Absolutism and the Birth of the Public Sphere. A Critical Wiew of a Model», en: Rospocher, M. (ed.), Beyond the public sphere: opinions, publics, spaces in early modern Europe, Bologna, Il Mulino / Berlin, Duncker \& Humblot, 2012, pp. 53-72.

16 Ibíd., p. 140; íd., "Der "Nomos" nach 1945 bei Carl Schmitt und Jürgen Habermas, en: forum historiae iuris. Internetzeitschrift für Rechtsgeschichte, Marzo (2006). Disponible en: http://www.forhistiur.de/zitat/0603mehring.htm

17 Cohen, J. L. y Arato, A., Civil Society and Political Theory, Cambridge, Mass. \& London (England), The MIT Press, 1992, pp. 231-251.

18 Cohen J. L. y Arato, A., Civil Society and Political Theory, o. c., pp. 241-246, 252-254.

19 Además de los trabajos de R. Mehring ya citados, que exponen sintéticamente la polémica, ver los artículos que la plantean: KenNedy, E., «Carl Schmitt und die "Frankfurter Schule". Deutsche Liberalismuskritik im 20. Jahrhundert», en: Geschichte und Gesellschaft. Zeitschrift für Historische Sozialwissenschaft, no 12 (1986), pp. 380-419; Preuß, U. K., "Carl Schmitt und die "Frankfurter Schule". Deutsche Liberalismuskritik im 20. Jahrhundert. Anmerkungen zu dem Aufsatz von Ellen Kennedy», en: Geschichte und Gesellschaft. Zeitschrift für Historische Sozialwissenschaft, $\mathrm{n}^{\circ}$ 13-3 (1987), pp. 400-418.

20 Mehring, R., Carl Schmitt zur Einführung, o. c., p. 140.

${ }^{21}$ Citado según la versión de Popper, K. R., The Open Society and Its Enemies, I, o. c., pp. 186-187. Cfr. Gerhardt, V., Licht und Schatten der Öffentlichkeit, o. c., pp. 42-43; íd., Öffentlichkeit, o. c., pp. 59-64. Huellas más remotas de esta concepción de la publicidad en la antigua Grecia podrían rastrearse ya en los llamados tiempos oscuros, con la influencia 
noción que pasará por autores como Bartolomé de las Casas, Francisco Suárez, John Milton, James Harrington, John Locke e Immanuel Kant, que le dan fundamento, por los Federalistas norteamericanos y el Abate Saint Pierre, que la fortalecen, y por quienes la profundizan, como John Stuart Mill, Ferdinand Tönnies, los ya mencionados H. Plessner y K. R. Popper, así como John Dewey, Karl Jaspers, Hannah Arendt, hasta los más recientes John Rawls y Jürgen Habermas ${ }^{22}$.

Junto a los motivos teóricos y sistemáticos para defender el papel insustituible de la noción de esfera o espacio público en el concepto de la política, cabe añadir algunos más, que se refieren a su contribución a una necesaria renovación de la filosofía política contemporánea, que precisamente se podría articular en torno a ella, en tanto la publicidad se muestra como un concepto clave para abordar algunas de las cuestiones políticas actuales más relevantes y candentes, por ejemplo: a) la transformación de las relaciones y las delimitaciones recíprocas entre los conceptos de público y privado; b) el debilitamiento del sentido de lo común en las sociedades de la modernidad tardía, por la fragmentación de los discursos, los enroques identitarios o por la exacerbación narcisista de una perspectiva individualista de los derechos; c) la incapacidad de los espacios urbanos actuales para contribuir a la construcción de civilidad o ciudadanía; o, d) la necesidad de dar un nuevo sentido al cosmopolitismo en el marco de la globalización ${ }^{23}$.

\section{CRÍTICAS Y CRISIS:LA IMPORTANCIA POLÍTICA DE UNA RAÍZ COMÚN}

La relación «crítica»-«crisis» pasó sorprendentemente desapercibida durante siglos, incluso para la propia época que la fraguó. Mientras que crítica es una de las palabras clave del siglo XVIII, crisis, en cambio, fue muy poco usada y de ningún modo es un concepto central de este período ${ }^{24}$. Lo que lleva a Reinhart Koselleck a su tesis es precisamente el hecho de que el Siglo de las Luces pareciese ignorar la relación entre la Crítica, que se comienza a ejercer en él de modo sistemático —al punto de que en Pierre Bayle «crítico» deviene sinónimo de «racional» — ${ }^{25}$, y la crisis del Antiguo Régimen que se avecinaba. El encausamiento crítico que la Ilustración promueve contra el statu quo de su tiempo es lo que genera la crisis, en igual medida que la crítica se oculta —incluso a sí misma- el sentido político de la crisis ${ }^{26}$.

«Crítica» $\mathrm{y}$ «crisis» derivan del verbo кpíveıv, en griego antiguo «separar, elegir, juzgar, decidir» y también «medirse con, luchar, combatir». «Crisis» significaba

fenicia —y de ella remontaría a las más viejas culturas de Oriente-, tal como queda reflejada en algunas prácticas testimoniadas por Homero y, sobre todo, en la construcción de ágoras y areópagos como espacios e instituciones de lo público en las polis: cfr. Ibíd., pp. 64-68; ver también aquí, infra, nota 33.

22 Cfr. Gerhardt, V., Licht und Schatten der Öffentlichkeit, o. c., pp. 43-44. Más ampliamente: Gerhardt, V., Öffentlichkeit, o. c., Capítulos 1 y 2.

23 Innerarity, D., El nuevo espacio público, Madrid, Espasa Calpe, 2006, pp. 13-28.

24 Koselleck, Kritik und Krise, o. c., pp. 132, 196; Koselleck, «Krise», o. c., p. 620.

25 Raвotnikof, N., En busca de un lugar común: el espacio público en la teoría política contemporánea, México, Universidad Nacional Autónoma de México, 2005, p. 97.

26 Koselleck, Kritik und Krise, o. c., pp. 5-6. 
a la vez el aspecto subjetivo, la crítica en tanto juicio, veredicto o decisión, y el objetivo, una situación de pugna o escisión. El significado jurídico es primario en ambas acepciones: ciudadano es quien participa de la dignidad y oficio judicial

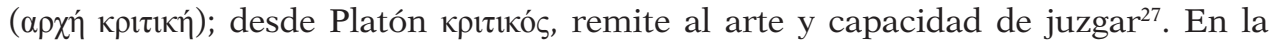
Biblia de los LXX, крíøıৎ alude a la manifestación escatológica de Dios como juez y su decisión sobre la salvación o condenación de los humanos. Crisis pasa al latín con el sentido forense centrado en la medicina y así entra al castellano: «Días críticos, llaman los médicos aquellos en que se puede hacer juicio y discurso de la enfermedad del paciente ${ }^{28}$. Pero en el siglo XVIII crítica se aleja llamativamente de la riqueza semántica originaria de crisis, para limitarse a designar un arte de enjuiciar y apreciar, del que queda excluida la gravedad de la decisión que todavía se apreciaba en los sentidos teológico, jurídico y médico. De ahí el muy diferente peso que connota el adjetivo "crítico» si se usa en referencia a la/s «crisis» o a la/s "crítica/ $\mathrm{S} »^{29}$. Lo grave de este divorcio entre crítica y crisis en la época ilustrada es que «la crítica precipita la crisis pero no la asume como tal, es decir, como crisis objetiva que exige una decisión política.» De ese modo la crisis quedará —Koselleck dixit—, o bien diluida en una filosofía de la historia, i. e., del "progreso», o bien resuelta en una guerra civil que enmascara su carácter político bajo el concepto de revolución, una vez la crítica, que inicialmente se auto-comprende como social y apolítica, se vuelva contra sí misma ${ }^{30}$.

Como expresión de la naciente sociedad civil burguesa, la esfera pública ilustrada nace, según Koselleck, lastrada por ciertas limitaciones políticas y algunos peligros constantes. La crítica del Estado, abordada desde una moralidad (o sociedad) presuntamente apolítica, arriesga hacerse impolítica o antipolítica, a fuer de querer ser solo social, sociedad civil, y se erige en abanderada de la verdadera "publicidad» como principio. Sin ceder al decisionismo, lo político ha de incluir, sí, la decisión — pace Schmitt—y precisamente las crisis son momento de decisiones, pero Koselleck identifica de continuo Estado (incluso absolutista) con política sin más, excluyendo de antemano la posibilidad de una esfera pública, civil y política, al aceptar la cesura entre los momentos de la decisión y de la discusión. Sin embargo, pese a Koselleck, la crisis del absolutismo no fue la crisis de lo político tout court. Su planteamiento «tiene la virtud de mostrar lo que ocurre cuando la gente vive la política como un territorio extranjero y lo que puede ocurrir cuando, en la conquista de ese territorio, el único equipo con el que se cuenta es el de la pureza moral» ${ }^{31}$. La lección que Koselleck enseña sub contrario es que la política precisa de esferas públicas libres, sin las que la crítica del presente desde lo moral y lo social estaría inevitablemente condenada a la anulación o al exilio de lo político.

27 Koselleck, Kritik und Krise, o. c., pp. 196-199.

28 Covarrubias y Horozco, Sebastián de, Tesoro de la lengua castellana o española, Universidad de Navarra/Editorial Iberoamericana, 2006, p. 632. Ver también: CorominAs, J. y Pascual, J. A. (1989). Diccionario Crítico Etimológico Castellano e Hispánico, Madrid, Gredos, 1989, p. 182.

29 Koselleck, Kritik und Krise, o. c., p. 197; Koselleck, «Krise», o. c., 1982.

30 Raвotnikof, N., En busca de un lugar común, o. c., pp. 98-99, 109.

31 Cfr. Rabotnikof, N., En busca de un lugar común, o. c., pp. 92, 103-110. 


\section{LA DISTINCIÓN PÚBLICO/PRIVADO Y LAS ESFERAS PÚBLICAS COMO ESPACIOS DE LA CRÍTICA}

Por contraposición a "privado» y «privacidad», «público» y «publicidad» poseen tres sentidos básicos: $1^{\circ}$, público es lo común y lo general, frente a lo individual y particular; $2^{\circ}$, público es lo manifiesto y ostensible, lo sabido o ampliamente conocido, por contraste con lo oculto o secreto; y $3^{\circ}$, público es lo abierto, lo (plena y universalmente) accesible, en oposición a lo cerrado, restringido, exclusivo ${ }^{32}$. Estos tres rasgos de lo público presentan entre sí tensiones que las tesis koselleckianas acentúan. En tanto que lo común y lo general, lo público oscila entre la identificación absolutista o totalitaria con lo estatal y una caracterización más liberal con un ámbito social, intermedio entre lo político y lo privado, pero Koselleck consagra la equiparación de lo público y lo político con lo estatal que instauró el absolutismo. De lo público en tanto que lo manifiesto y abierto nace la reclamación de una esfera pública políticamente activa, por parte de quienes defienden la necesidad de una crítica moral (social) de la acción política, frente a quienes consideran las puras pretensiones morales incompatibles con la especificidad de la política. En suma, estas tres acepciones de lo "público» (lo colectivo, lo manifiesto y lo abierto) si acaso alguna vez se aunaron armónicamente pudo ser en las agorai de la Antigüedad griega, al menos tal como las interpretamos desde la Modernidad ${ }^{33}$, pues parecen seguir constituyendo actualmente la imagen, en cierto modo idealizada, de lo que han de ser las esferas o espacios públicos ${ }^{34}$ : lugares o medios (entornos e instrumentos) de comunicación comunes, compartidos o compartibles, en los que se presentan manifiestamente, para ser expuestas a discusión y/o deliberación, de manera abierta, todas y cualesquiera cuestiones que se considere incumben a todos y cualesquiera miembros de un grupo humano sin distinción, y tendencialmente a toda la humanidad ${ }^{35}$.

Como principio político, la publicidad presupone: distinción entre bien o interés público y bien o interés privado; delimitación de lo público establecida a la luz pública; participación ciudadana en argumentaciones y decisiones; y menor riesgo de malversación de lo común gracias al control ejercido por el público ${ }^{36}$. La esfera

32 Rabotnikof, N., «Público / Privado», en: Debate feminista (México), nº 18 (1996), pp. 3-13.

${ }^{33}$ Las poleis adoptan muy diferentes formas, pero se caracterizan siempre por la existencia en ellas de espacios públicos, i. e., de lo «demion» y lo «koinon», de todo el pueblo en común. Aunque los templos de las divinidades de la polis y las necrópolis también son lugares públicos, a partir del siglo VIII a. C. es el agoré el espacio público que más importancia va adquiriendo frente a los ámbitos domésticos (oikos) y sagrados. De ella, como espacio de reunión y comunicación de toda la comunidad, vacío, neutral, libre de dominios humanos o divinos, aunque con la protección de algunas deidades, o sea, de este espacio específicamente político parten las dinámicas que desencadenarán los cambios institucionales de la polis. Cfr. HöLscher, T., Öffentliche Räume in frühen griechischen Städten, Heidelberg, Universitätsverlag C. Winter, 1998, pp. 15-16, 29-45.

34 «El ágora y el areópago son hasta hoy símbolos de lo que significa esfera pública.»: Gerhardt, V., Öffentlichkeit, o. c., 59.

35 RAвотNikof, N., «Lo público y sus problemas: notas para una reconsideración» en: Revista Internacional de Filosofía Política, no 2 (1993), pp. 75-98. Para esto, ver especialmente, pp. 76-81.

36 Ibíd., pp. 75-98. 
pública desempeña una función de restricción normativa del poder absoluto y de limitación de cualquier pretensión de un ejercicio directo de la soberanía, sea absolutista, fascista, o un despotismo democrático. De ahí que, a pesar de lo que mantiene Koselleck, una esfera pública lo es, solo si efectivamente es espacio de la crítica. Puesto que se gesta justo cuando se articula la diferencia entre opinión en sentido genérico y public opinion, como resultado de la criba crítica de los juicios particulares en la discusión abierta, la esfera pública se acabará definiendo por su función formadora de la opinión pública, que «tan sólo puede ser producida, conforme a su propia idea, bajo el supuesto de un público raciocinante» ${ }^{37}$. En la esfera pública se trata, precisamente, de pensar la diversidad de las opiniones junto con la pretensión de un conocimiento universalmente válido, al menos en potencia. La pluralidad de los pareceres se convierte, por tanto, en condición de búsqueda de lo correcto, siempre desde el punto de vista de un juicio personal propio ${ }^{38}$. ¿Resulta afectada, entonces, esta caracterización de la esfera pública, por la imputación de «estratégica» que Koselleck lanza sobre la reivindicación burguesa moderna de un ámbito de discusión, comunicación y crítica puramente social, que desde la moralidad enjuicia al Estado absolutista? Examinemos su argumento.

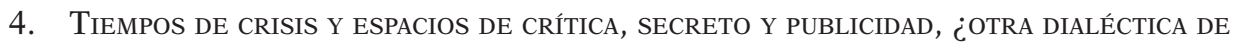 LA ILUSTRACIÓN?}

Durante el siglo XVIII el «estamento» burgués, como impulsor de una forma de organización social emergente, se apropia de la separación entre moral y política instaurada por el absolutismo. Una moral laica, basada en el juicio autónomo de los ciudadanos, al margen de la Iglesia y del Estado, se erige en instancia suprema de crítica de la política ${ }^{39}$. Con su tajante división entre lo público - la ley- y lo privado - las convicciones morales - y con la estricta primacía de lo públicoestatal, el Estado absolutista surge como remedio al estado de «guerra civil» entre confesiones religiosas. La naciente moral burguesa, que acabará desbancando al poder del Estado soberano, se constituye, frente a este y frente al poder religioso, como un "tercer poder ${ }^{40}$, pretendidamente "social». Pero la red de asociaciones científicas, clubs de debate, logias y otros grupos no es para Koselleck germen de esfera pública, sino un entramado de hábil estrategia conspiradora, que formando una libre sociedad de ciudadanos que pretenden entenderse a sí mismos al margen del Estado, pone las bases para romper desde dentro el régimen absolutista. Los clubs se resguardan de la vigilancia estatal con la excusa de que sus actividades y sus discursos son solo morales y "sociales» ${ }^{41}$, al tiempo que se colocan como jueces morales inapelables de la legitimidad del Estado. El estricto sigilo que como asociaciones privadas mantienen sobre el contenido de sus discusiones, no impide

37 Habermas, J., Kultur und Kritik, Frankfurt a.M., Suhrkamp, 1973, p. 62.

38 Gerhard, V., Öffentlichkeit, o. c., pp. 148-150.

39 Koselleck, R., Kritik und Krise, o. c., pp. 18-32, 161-169.

40 Ibíd., pp. 47, 57.

41 Ibíd., pp. 49-61. 
que por toda esa nueva organización que frente al Estado están contribuyendo a formar, la sociedad, se vayan extendiendo opiniones, juicios y principios morales de una nueva virtud que cuestiona las instituciones estamentales y estatales del Antiguo Régimen ${ }^{42}$. Como afirma J. Locke en Inglaterra, son los ciudadanos agrupados en la sociedad civil — no como meros particulares- quienes establecen, mediante su aprobación o rechazo lo que se ha de estimar o no como virtuoso. Mediante la ley de la opinión pública, que significativamente Locke denomina «the law of private censure», la Crítica, «censura» o veredicto de la ciudadanía se justifica a sí misma como lo justo y lo verdadero, y se convierte en poder ejecutivo de la nueva sociedad ${ }^{43}$. En la Europa continental, esa legislación moral cívica, convertida en un factor político indirecto, no necesitará enfrentarse abiertamente al Estado, pues se siente legitimada por el sentir común de la sociedad, con la doble certeza de poseer por principio la razón y de que la continua revisión de los juicios es el "progreso»" que deja continuamente atrás las leyes estatales. Los ciudadanos radicalizan así la contraposición absolutista entre moral y política hasta convertirla en una polarización que aparece a la vez como síntoma y como instigadora de la crisis en ciernes ${ }^{44}$.

La retroalimentación recíproca crítica-crisis con su dinámica de (auto) ocultamiento de las pretensiones políticas que subyacen a la crítica moral del Estado absolutista por parte de la sociedad civil, tiene su base en la tensión publicidadsecreto señalada más arriba al contraponer público frente a privado. «Ilustración y secreto surgen desde un principio una junto al otro, como una pareja histórica de gemelos ${ }^{45}$. Dualidad que resulta de la apropiación de la escisión absolutista entre lo privado y lo estatal. La Ilustración va ampliando ese espacio interior de la conciencia, ocultando cada aspiración a lo estatal con el velo del secreto ${ }^{46}$. Esta doble dialéctica cruzada (crítica-crisis, publicidad-secreto) tiene su expresión en dos de las instituciones que, según Koselleck, imprimen su sello a la Ilustración europea continental: la Republique des Lettres y las logias masónicas. Respecto a estas, sostenía Gotthold Efraim Lessing en sus Diálogos para francmasones (1778) que el sigilo sirve solo a la ocultación de las consecuencias políticas de los planes morales, humanitarios, de superación de los Estados absolutistas ${ }^{47}$. De este modo, los planes políticos quedan ocultos, en cuanto políticos, incluso para los propios agentes, en una «dialéctica» que forma parte de la que se da entre crisis y crítica, que estaba ya implícita en la antítesis moral entre sociedad y Estado absolutista. Y será la que (por la vía indirecta del encausamiento crítico del poder) terminará con la destrucción de éste ${ }^{48}$. En esta tensión entre secreto y publicidad se puede reconocer con J. Habermas una «contradicción» interna a la Ilustración, llamada a disolverse cuando el ejercicio público de la razón desplace a las formas representativas de

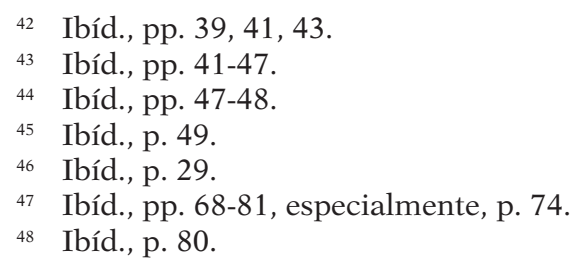


publicidad $^{49}$. En lo que respecta a la Crítica ejercida por la República de las Letras, Koselleck identifica un notorio paralelismo con la discreción masónica. Pues, al igual que los masones por medio del secreto se distancian del Estado, en principio para sustraerse a su influencia, pero, precisamente sobre la base de esta separación aparentemente apolítica, su objetivo final es llegar a ocuparlo, del mismo modo la crítica se aparta inicialmente de «la política», para luego a continuación, en razón de este apartamiento, aparentemente neutral, extenderse hacia el Estado y someterlo a sus dictámenes. La crítica, entonces, como quedará al descubierto, sucumbe así a su propio aparentar neutralidad y se convierte en hipocresía ${ }^{50}$. La representación escénica, como las demás instancias críticas que va configurando la burguesía, expresa y profundiza la crisis del Estado absolutista ${ }^{51}$. Luego, cuando alcance el poder, la Crítica dejará al descubierto su latente ambivalencia ante la política y su autoengaño radical, o "hipocresía metafísica ${ }^{52}$, en la que incurre toda crítica ilustrada cuando pasa de lo moral-social a la política y que le impide ver que el nuevo poder «social» que ella está generando es tan «político» como el que ella enjuicia ${ }^{53}$.

En definitiva, en el proceso de desenmascaramiento, los críticos terminan enredándose ellos mismos, concluye Koselleck. Así, cuando Immnauel Kant, el filósofo del pensamiento crítico, exija que «la verdadera política no sólo debería proceder de manera sincera, sino también abierta» y que «no le estaría permitido actuar según máximas que se deban encubrir ${ }^{54}$, el proceso se completa y la Crítica, que inicialmente se había apartado del Estado para imperar sin trabas, borra los límites que ella misma se había trazado y se erige en soberana sobre la esfera pública, arrogándose incluso con las funciones del secreto de Estado. De manera que ya no es la Crítica la que tiene que esconderse, sino que son ahora Estado e Iglesia quienes buscan ocultarse del rigor de los juicios de este nuevo «tercer poder». Pues

49 Habermas, J., Strukturwandel der Öffentlichkeit, o. c., pp. 95-97.

50 Koselleck, R., Kritik und Krise, o. c., pp. 81-82.

51 Un proceso que Koselleck ejemplifica con la conferencia de Friedrich Schiller titulada «El escenario teatral considerado como institución moral», que pronuncia ante la Sociedad alemana de Mannheim (26.6.1784) y se publica en Thalía ( $\left.\mathrm{n}^{\circ} 1,1785\right)$, revista dirigida por el propio poeta y dramaturgo, como "¿Qué efecto real puede causar una escena bien montada?»: Schiller, F., "Was kann eine gute stehende Schaubühne eigentlich wirken?», en: Sämtliche Werke. Ed. de G. Fricke y H. G. Göpfert. Vol. V. München, Carl Hanser Verlag, 1989, pp. 818-831.

52 Koselleck, R., Kritik und Krise, o. c., p. 96. Aquí Koselleck adapta para su propio argumento la distinción entre esta «hipocresía metafísica», cabe decir ontológica, y la hipocresía meramente psicológica, el ocultar consciente de los propios pensamientos y deseos, que se planteaba en: Merleau-Ponty, M., Phénomenologie de la perception, Paris, Gallimard, 1945, p. 190.

53 Rabotnikof, N., En busca de un lugar común, o. c., p. 96.

54 Koselleck cita aquí un pasaje de los póstumos de KanT, de «Trabajos preparatorios para el tratado sobre Teoría y praxis (1793) y de la Teoría del Derecho (1797)», cfr. KANT, I., Versmischte Schriften, ed. de Karl Vorländer, Leipzig, Felix Meiner Verlag, 1922, pp. 294295. Sobre la formulación kantiana del principio de publicidad en su obra publicada y su actualidad en relación con la vindicación - frente a Koselleck - de las esferas públicas críticas, ver en este trabajo infra: nota 99. 
un Estado que no acata los mandamientos de la razón crítica sólo puede recibir un «respeto simulado»; mientras que, por contra, a un «respeto no simulado» podría aspirar tan solo aquel si se somete a los jueces ilustrados. Tan segura de sí se siente la Crítica, concluye Koselleck, que, según ingenioso neologismo de su invención, se vuelve «hipo-crítica», puesto que ella se permite arrojar sobre el Estado también la culpa de esa hipocresía ${ }^{55}$.

¿Y qué ocurre con la crítica en las esferas públicas actuales, desarrolladas en y pensadas desde las recientes crisis, con nuevas movilizaciones sociales y nuevas tecnologías de la información y la comunicación (TIC)? Al expresar su desconfianza respecto a la idoneidad de lo digital para la política, Byung-Chul Han parece retomar hoy el contexto de controversia de las tesis de Koselleck, en tanto recupera determinados conceptos schmittianos. Así, la soberanía, que Han propone redefinir hoy como capacidad de disposición sobre las shitstorms en la red; o la volonté générale rousseauniana, que reinterpretada por Schmitt implica —como para Han la democracia digital - una unanimidad sin comunicación ni discusión, sin grupos ni distinciones sociales, que antes anulan que respetan las diferencias individuales. Echa de menos también Han, en este nuevo mundo digital, nociones como Nomos de la tierra, la distinción amigo/enemigo, o aquel «coraje para el secreto» que Schmitt, frente al principio de publicidad, rebajado por él a mero "postulado», reivindicaba en los años veinte como inherente a toda "gran política» ${ }^{56}$. Asumiendo expresamente una concepción de lo político como «acción estratégica» en la que desempeña un papel fundamental lo arcano, se une Han al desprecio burlesco de Schmitt por una política incapaz de guardar secretos y que todo lo desenvuelve —en alusión al cómico personaje de La flauta mágica del masónico Wolfgang A. Mozart- "en un escenario de Papageno ${ }^{57}$. Ya en sus acerbas críticas de La sociedad de la transparencia planteaba Han una recusación del nexo entre esfera pública y exigencia incondicional de transparencia, frente al que propone recuperar para las sociedades contemporáneas el «derecho al secreto» que defendiera Georg Simmel como garante de la tensión y la vitalidad de las relaciones sociales. Frente al imperativo del esclarecimiento extremo en las sociedades de la hiper-comunicación e información, que él denuncia como «coacción» y «violencia», evoca Han la referida valentía para el secreto propugnada por C. Schmitt ${ }^{58}$. Desde ahí, se explican tanto la sumaria reprobación del Partido Pirata alemán con su reivindicación de la transparencia ${ }^{59}$, como la descalificación de «las olas de indignación», a las que Han considera incapaces de formar esfera pública, pues:

$[\mathrm{N}] \mathrm{o}$ forman un nosotros estable que muestre una estructura de preocupación por el conjunto de la sociedad. La preocupación [cuidado, Sorge] de los denominados ciudadanos airados no es por el conjunto de la sociedad, sino en buena medida una preocupación por sí mismos. De ahí que se disperse de nuevo con rapidez ${ }^{60}$.

55 Koselleck, R., Kritik und Krise, o. c., pp. 101-102.

56 Han, B., Transparenzgesellschaft, o. c., p. 84; íd., Digitale Rationalität, o. c., pp. 13-14, 67-70, 103,106.

57 Han, B., Transparenzgesellschaft, o. c., pp. 14-15.

58 HaN, B., Digitale Rationalität, o. c., pp. 23-24, 43.

59 HaN, B., Transparenzgesellschaft, o. c., pp. 7-9, 15-16.

60 Han, B., Im Schwarm, o. c., p. 16. 
Sin embargo, reconocer la necesidad de espacios preservados frente al brillo, cegador a veces, de lo público ${ }^{61}$, o admitir que las «sombras», como la otra cara de las luces de la esfera pública no siempre han de tener sentido peyorativo ${ }^{62}$, no justifica suscribir esta revitalización de la política absolutista del arcano para la era cibernética. En la reticencia del heideggeriano Han frente a las nuevas esferas públicas cabe ver hoy una repetición cansina de juicios apocalípticos sobre los medios de masas, que pudieron tener sentido a comienzos del $\mathrm{XX}^{63}$. Veamos ahora, pues, el alcance y los límites de la aplicación actual de la dialéctica crítica-crisis, y su entrelazamiento con la tensión publicidad-secreto, que se examinará más extensamente en otro lugar, como otra posible «dialéctica de la Ilustración».

\section{NueVas ESFERAS PÚblicas, PARA EStOS TIEMPOS CRíticos}

Diversos acontecimientos de estas últimas décadas apuntan a que la crisis contemporánea de la política y de las instituciones del Estado moderno está siendo acompañada y, al menos en parte, también incentivada, por el surgimiento de nuevas formas de esfera pública. Las recientes movilizaciones sociales y políticas en el mundo y en España (manifestaciones antiglobalización, contra las guerras en Irak, primaveras árabes, $15 \mathrm{M}$, Occupy Wall Street) han tenido como coprotagonistas a las TIC, conformando un fenómeno que ha provocado la reflexión de teóricos de la sociedad y la cultura de la más variada tendencia. Nuevas formas de comunicación, discusión y opinión políticas, basadas en el uso de los nuevos medios digitales han puesto definitiva y radicalmente en cuestión los modelos de esfera pública modernos y del siglo XX, centrados aún en los medios de comunicación de masas.

Si la crisis ilustrada del Antiguo Régimen gestó las esferas públicas como espacios críticos modernos, la crisis de la Modernidad en que hoy nos hemos instalado ha potenciado, con el paso a la sociedad post-industrial, las posibilidades que la comunicación electrónica y la cultura digital abren para configurar nuevas esferas públicas regidas por la inmediatez, la conectividad y la interactividad. Los nuevos movimientos sociales (feminista, ecologista, pacifista), que en la segunda mitad del siglo XX entraban en escena desplazando a los «viejos» del centro de los debates públicos, se encontraron, por sus estilos de acción y formas de organización, en mejores condiciones para hacer suya esta nueva publicidad digital, que está transformándolos también a ellos, al gestar movilizaciones inéditas, como la altermundialista o el 15M, nuevos estilos de activismo (ciberfeminismo), nuevas formas de comunicación y de cultura cívica ${ }^{64}$, e incluso nuevas formaciones políticas, como Podemos en España ${ }^{65}$. Puesto que en muchos países se ha implementado ya la administración electrónica, hay quienes entienden que lo digital ha de transformar

61 Arendt, H., The Human Condition, Chicago/ London, University of Chicago Press, 1958.

62 Gerhardt, V., Licht und Schatten der Öffentlichkeit, o. c., pp. 25-30, 33-36.

63 Ibíd., pp. 29-36.

64 Dahlgren, P., «Jóvenes y participación política. Los medios en la Red y la cultura cívica», en: Telos, 89 (2011), pp. 12-22. Disponible en: https://telos.fundaciontelefonica.com/

65 Vallespín, F., "La gestión de la democracia en el entorno digital. Política y nuevas redes» en: Telos, 100 (2015), pp. 45-47. Disponible en: https://telos.fundaciontelefonica.com/. Se cita p. 46. 
completamente lo político. Así el ciberactivismo 2.0 exige más democracia electrónica, aplicar las TIC al ejercicio de todos los derechos cívicos y políticos, incluido el voto $^{66}$. Ya alguien auguró hace décadas el paso de la utopía del trabajo a la utopía de la comunicación ${ }^{67}$; otros, en cambio, ven hoy como amenaza el advenimiento de «una democracia digital en la que el botón de Me gusta sustituye por completo a la papeleta electoral» ${ }^{68}$. En lenguaje de Koselleck cabe decir, pues, que también hoy vuelven a retroalimentarse crítica/s y crisis. Crisis de la política, de las esferas públicas y de los media ${ }^{69}$, que se incentivan mutuamente unas a otras. Así en la sociedad española actual, el descrédito de lo político encuentra «un eficaz altavoz en toda la retahíla de reacciones, más o menos viscerales o expresivas, que se recogen cotidianamente en la Red a medida que se van desvelando casos de corrupción, se narran nuevos desahucios o aparecen nuevas medidas de gobierno ${ }^{70}$.

Desde lo profundo de la crisis se atisba una paulatina transformación, de imprevisibles consecuencias, de las diferentes formas políticas de representación (líderes, partidos), en una nueva "política de la presencia» de una nueva ciudadanía que, a través de los medios digitales, veloces, inmediatos, irreflexivos si se quiere, gana en influencia, gestando estas nuevas esferas públicas, en las que, parece, pasarán irremediablemente a segundo plano quienes - voluntariamente o por fuerza - se queden sin conectarse a las redes ${ }^{71}$. En fenómenos como el movimiento de «indignados» se observa cómo los espacios virtuales se interconectan con las manifestaciones, asambleas, reuniones, en las calles y plazas de ciudades y pueblos, radicalizan y generalizan la crítica, en tanto se autoproclaman voz de la gente, de la ciudadanía, del pueblo, pidiendo «Democracia Real, ¡Ya!» a los gritos de «No nos representan», o «Lo llaman democracia y no lo es», y plantean un abierto cuestionamiento de la legitimidad real de legisladores y gobernantes, dando expresión a la carga de sospecha que pesa sobre las formas políticas establecidas, en especial el sistema de representación mediante partidos y profesionales de la política, lastrados por decenios de decepción, descrédito, ineptitud y corrupción acumuladas. Aquí también, como la Ilustración respecto al Antiguo Régimen, la crítica nace de, y al mismo tiempo «convoca» y provoca, una crisis de la política que los críticos creen que se limitan a señalar y denunciar desde la sociedad.

En estas movilizaciones aflora, desde luego, una conciencia bastante definida de que se está dando voz a unas circunstancias sociales críticas (Stop deshaucios),

66 Fernández Prados, J. S., "Ciberactivismo: conceptualización, hipótesis y medida» en: Arbor, vol. 188, $\mathrm{n}^{\circ} 756$ (2012), pp. 631-639.

67 Jürgen Habermas en el discurso que pronuncia en España ante el Congreso de los Diputados en el año 1984. Cfr. Una versión abreviada como artículo de prensa: HABERMAS, J., «El fin de una utopía» en: El País. 9.12.1984. Disponible en: http://elpais.com/diario/1984/12/09/ opinion/471394806_850215.html. La elaboración extensa aparecerá en: HABERMAS, J., «Die Krise des Wohlfahrtstaates und die Erschöpfung utopischer Energien», en: íd., Die Neue Unübersichtlichkeit. Kleine Politische Schriften V, Frankfurt a. M., Suhrkamp, 1985, pp. 141-163.

68 Han, B., Im Schwarm, o. c., p. 85.

69 Cfr. Bennett, W. L. y Segerberg, A., «La comunicación en los movimientos. De los medios de comunicación de masas a las redes sociales», Telos, 98 (2014), pp. 58-70; Fuchs, C., «Retos para la democracia. Medios sociales y esfera pública», Telos, 98 (2014), pp. 71-82. Disponibles en: https://telos.fundaciontelefonica.com/

70 Vallespín, F., art. cit., p. 46.

${ }^{71}$ Ibíd., pp. 47-48. 
o ante una crisis generalizada de referentes políticos, se intenta, como en el 15M, hacerle frente con nuevo lenguaje y nuevos códigos (insistencia en lo asambleario, rechazo de liderazgos y portavocías, ausencia de representantes fijos, exigencia de consensos amplios para los acuerdos $)^{72}$, que en buena medida sencillamente redescubren nociones características del imaginario de la esfera pública. En sus comienzos, Podemos adopta la potente metáfora de igualdad y simetría del círculo para denominar a sus ámbitos primarios de organización, expresando con ello un rechazo frontal a los distintivos jerárquicos de estatus que suelen acompañar a los representantes políticos, intentando desmarcarse de las identificaciones habituales (dietas, sueldos, discursos) de las élites políticas, para mejor asemejarse a la ciudadanía «común» (o media) a la que en definitiva también se quiere llegar a representar, solo que de otro modo. Posteriormente vendrá la sustitución paulatina de una política de consensos de corte asambleario, por una de liderazgo y estructura de partido al estilo clásico ${ }^{73}$.

El paralelismo entre la situación presente y las tesis de una crítica pretendidamente solo «moral» o «social» de la política requiere, sin embargo, importantes matizaciones. La correspondencia entre los ejemplos actuales y los análisis koselleckianos es limitada. Ni el movimiento indignado, ni menos aún Podemos parecieron precisar reivindicarse expresamente como apolíticos para plantear la críticacrisis de la política. A pesar de la contundencia de los lemas de las manifestaciones, ni aun en los análisis más extremados de la situación parece suponerse que falten tanta democracia o derechos como para que haya que encubrir los propósitos políticos, como cuando la Ilustración se enfrentaba a los Estados absolutistas. Es igualmente cierto, sin embargo, que tanto en el 15M como en los inicios de Podemos está presente un rechazo a lo que es de facto la política — sistema de partidos, «clase política» o «casta»— que, en nombre del pueblo, «la gente», agita en forma de crítica radicalizada todo lo que de objetivamente crítico tiene la actual crisis, para apuntar desde ahí a otra política. A la vez, en este proceder cabría detectar esa ceguera o «hipocresía» inconsciente acerca del carácter verdaderamente político de una crítica hecha pretendidamente desde fuera de esa política. En esta clave podría leerse aquel «Documento: Pre-Borrador de ponencia política» que da a conocer Podemos en el verano de $2014^{74}$, cuando está ya en vías de constituirse como partido político. En él se lleva a cabo un análisis del presente como «la crisis del régimen de 1978», "una situación de agotamiento orgánico», por la que atraviesa el Estado español, que «va más allá de la deslegitimación de sus élites políticas y que afecta a componentes centrales del sistema político y la institucionalidad». Este diagnóstico

72 Castells, M., Redes de indignación y de esperanza. Los movimientos sociales en la era de Internet, Madrid, Alianza, 2012, pp. 130-131.

73 Marzolf, H. y Ganuza, E., “¿Enemigos o colegas? El 15M y la hipótesis Podemos», en: EMPIRIA. Revista de Metodología de Ciencias Sociales, 33 (2016), pp. 89-110.

74 Las citas que siguen están tomadas de: Podemos, «Documento: Pre-Borrador de ponencia política. La crisis del régimen de 1978, Podemos y la posibilidad del cambio político en España», 2014. Recuperado de: http://ep00.epimg.net/descargables/2014/07/17/5cd191 130d9a7b5c4d297efb418a3ee7.pdf Agradezco a mi compañera del Grupo de Investigación Historia de la Filosofía. El ensayo español. Siglos XVI-XX, M ${ }^{\mathrm{a}}$ Dolores Maldonado Martínez, haber llamado mi atención sobre el interés filosófico de este documento. Su lectura en relación con las tesis de Koselleck es de mi responsabilidad. 
entronca de inmediato en el documento con el «movimiento $15 \mathrm{M}$ » al que se atribuye un papel fundamental en lo que a visibilizar y politizar la crisis se refiere. Para Podemos, en esta «disyuntiva política estratégica», frente a la «amplia y profunda ofensiva sobre el pacto social y político de 1978», que etiqueta como "deconstituyente» y "restauración oligárquica», la alternativa es una "apertura democráticoplebeya, posiblemente en un sentido constituyente». Las dinámicas de realimentación recíproca entre crítica y crisis y la dialéctica publicidad-secreto, analizadas por Koselleck, aparecerían aquí reflejadas. Con la crítica en nombre de «la calle», las «demandas ciudadanas» o la «unidad popular», el documento promueve activamente la crisis de un sistema definido en la ahora cuestionada Constitución de 1978 como «Estado social y democrático de Derecho», un «régimen» al que se enjuicia sumariamente como agotado, a fin de mostrar la necesidad de caminar hacia un nuevo Estado, posiblemente — cabe leer entre líneas- republicano, término que por cierto no aparece expresamente en ningún lugar del texto.

Respecto a la dialéctica público-secreto, en el contexto contemporáneo de la comunicación digital, con las nuevas esferas públicas post-crisis de la modernidad se pueden ver dos caras. Pese a las amenazas, latentes casi siempre, desenmascaradas a veces, de control y vigilancia masiva ${ }^{75}$, se multiplican las posibilidades para el sigilo en la organización de manifestaciones o protestas, que intenten esquivar el control gubernativo, o para la difusión por vías en principio «privadas» (mensajería electrónica) de ideas políticas que buscan una (relativa) clandestinidad desde la que cuestionar el poder. También se abren nuevos espacios para todo tipo de delitos, incluido el terrorismo, y esto sin entrar en las ambiguas expectativas que despierta la posibilidad de un anonimato real en la denominada Deep Net, TOR o Onionland, temas que desbordan las pretensiones del presente trabajo. Quizá donde se pueda ver más claro cómo en el interior mismo de la dialéctica entre crítica y crisis juega un muy destacado papel la dialéctica entre publicidad y secreto — con su apelación a una crítica de la política y de los Estados, que se tiene que hacer pasar por solo moral y social- es en el caso de las filtraciones de Wikileaks ${ }^{76}$, con su desafío a la sinceridad del cumplimiento por parte de los Estados del imperativo kantiano de la publicidad de las máximas que rigen la acción política. Intervenciones hackactivistas como las de Edward Snowden incentivan y, a la vez, simplemente ponen de manifiesto la crisis de modelo de una política y de unos Estados que ciertamente ya no son absolutistas, pero sí parecen actuar a menudo de facto más conforme a la concepción schmittiana del Estado y la política, que conforme a los ideales de derechos humanos universales que proclaman. Ese tipo de situaciones contribuyen, como señala Manuel Castells con respecto a la «política del escándalo» y la "política mediática», a la "crisis mundial de legitimidad política», sin embargo, «el declive de la confianza pública no equivale a un declive de la participación política», pues la ciudadanía busca constantemente nuevas formas de movilizarse haciendo uso de los nuevos medios y de los nuevos espacios públicos ${ }^{77}$.

75 Bauman, Z. y Lyon, D., Liquid Surveillance. A Conversation, Cambridge, Polity Press, 2013.

76 Wilkens, A., Analog ist das neue Bio, Berlin, Metrolit-Verlag, 2015, pp. 42-46; SAmpedro Blanco, V., «Ciberactivismo. De Indymedia a Wikileaks y de Chiapas al Cuarto Poder en la Red», en: Telos, 98 (2014), pp. 94-96. Disponible en: https://telos.fundaciontelefonica.com

77 Castells, M., Comunicación y poder, Madrid, Alianza, 2009, pp. 388-389. 
El reconocimiento de la potencialidad de las tesis históricas de Koselleck para analizar las relaciones entre crítica-crisis y publicidad-secreto en nuestro presente no puede, pues, obviar la necesidad de una refutación del fondo de su planteamiento, desde el momento en que se asume la validez normativa de determinados rasgos de la forma de esfera pública burguesa. La cuestión de una esfera pública políticamente activa se inscribe en la vieja discusión entre moral y política, que enfrenta a quienes defienden la necesidad de corrección moral de la acción política con quienes admitirían un cierto grado de estrategia, necesario en la política como ámbito específico diferenciado de lo moral. Pero no es cuestión de disimulo o de encubrimiento más o menos (in)consciente de las intenciones políticas de la crítica, ni de toma indirecta del poder desde un proyecto moral particular, como supone Koselleck. Hoy, como en la época ilustrada, nuevos tiempos críticos engendran nuevos espacios de crítica, esferas públicas nuevas, con sus dialécticas entre publicidad y secreto, que aguzan con la crítica lo crítico de los tiempos. Frente a las acusaciones de «hipocresía» de Koselleck contra las esferas públicas, urge vindicar su pertinente papel de crítica política, ejercida desde el terreno intermedio de lo social, como permanente garantía del ejercicio de la libertad por la ciudadanía.

\section{Conclusión: ¡ESFERAS PÚBlicas y CRíticas, sí! EN —Y MÁS ALLÁ DE- LAS CRISIS}

La función de espacios críticos de las esferas públicas no implica la negación del carácter decisorio y rector de la política. Ya Aristóteles vinculaba la condición política de ciudadanía a "participar en las funciones judiciales y en el gobierno» ( $t \bar{o}$ metechein kriseos kai arches ${ }^{78}$, juntando en una sola dos actividades, la de juez y la de miembro de la asamblea ${ }^{79}$. El concepto aristotélico de política unía inseparable y significativamente la tarea del gobernar («archē») y la del juzgar («krisis»), aspecto este último que Koselleck acusaba a la época ilustrada de haber perdido, lo que propiciaba la denuncia de hipocresía, dirigida contra la crítica ejercida desde la sociedad hacia el Estado. Frente a las reticencias de una Hannah Arendt ante el concepto de lo «social», que recorren toda su obra ${ }^{80}$, porque, según ella, arruinaría la neta distinción entre lo público y lo privado, la reivindicación de la esfera pública como ámbito social de la crítica política cuenta hoy, además de con los actuales defensores del concepto de sociedad civil, como los propios Jean L. Cohen y Andrew Arato $^{81}$, con valedores teóricos tan destacados y diversos como: a) En primer lugar, Jürgen Habermas, el más representativo defensor teórico y práctico del potencial crítico de la esfera pública ${ }^{82}$, quien casi treinta años más tarde reconocía que, si volviese a escribir su obra de 1962, habría realizado una evaluación menos pesimista de las potencialidades de la esfera pública para la teoría de la democracia ${ }^{83}$, pues, los

78 Aristóteles, Política, traducción de Manuela García Valdés, Madrid, Gredos, 1988, 1275a 24.

79 Gerhardt, V., Partizipation. Das Prinzip der Politik, München, Verlag C. H. Beck, 2007, p. 26; íd., Öffentlichkeit, o. c., p. 319.

80 Cohen, J. L. y Arato, A., Civil Society and Political Theory, o. c., p. 647.

81 Ibíd., p. 178.

82 Gerhard, V., Öffentlichkeit, o. c., p. 226.

83 Habermas, Strukturwandel der Öffentlichkeit, o. c., pp. 49-50. 
espacios de la "publicidad» generan comunicativamente poder legítimo, en tanto gracias a ellos la acción política enraíza en el mundo de la vida, desde donde surgen los nuevos temas objeto de deliberación pública y se apuntan nuevas regulaciones normativas ${ }^{84}$; b) Charles Taylor, quien entiende la esfera pública como «un espacio de discusión que de manera autoconsciente se considera como situado al margen del poder» ${ }^{85}$; o, c) Ralf Dahrendorf, quien aboga por «el derecho, y en tiempos de crisis, la obligación [de los ciudadanos], de decir lo que desean y lo que no». Pues, «la cara aparentemente negativa [de la democracia], el control, la crítica y la protesta, puede ser más importante para la libertad» ${ }^{86}$.

Como ámbitos de intercambio de conocimientos u opiniones y de búsqueda del entendimiento en la sociedad, las esferas públicas poseen ciertamente dimensiones prepolíticas ${ }^{87}$. Forma parte, sin embargo, del genuino sentido de lo que es una esfera pública, el que sea política y social a un tiempo, y precisamente lo uno por lo otro. Las esferas públicas críticas son "políticas» porque dan voz a la auto-organización de las sociedades, hasta el punto de que bien se puede hablar de «la política como esfera pública organizada» ${ }^{88}$. Y es que con la esfera pública toma cuerpo en la sociedad el principio de «publicidad», que, junto con otros tres principios fundamentales (constitución, representación y participación), indisolublemente vinculados a él ${ }^{89}$, conforman la complicada e irrenunciable "cuadratura» de la política ${ }^{90}$. Solo un concepto normativo de este tipo puede dar cuenta de la complejidad y relevancia omnicomprensiva de lo político en la existencia humana. Una esfera pública independiente, con funciones de crítica política, representa además la posibilidad de pensar el paradójico concepto de una soberanía auto-limitada, a salvo de tentaciones neoabsolutistas, de las que no estarían exentos ni Estados ni movimientos sociales, ni la nueva - presunta- «alter-política» con sus formas no convencionales de acción ${ }^{91}$. La ambigüedad de la esfera pública frente a lo político se une y se superpone de este modo a una exigencia de secularidad radical de la política. La esfera pública, pues, que desde su lado social y extra-político critica todo ejercicio del poder, adquiere así su pleno sentido en la asunción de la falta de un absoluto en política ${ }^{92}$. Ni la política se arroga ningún sentido trascendente a la finitud de la existencia humana, ni admite ella misma llenar ese lugar vacío del absoluto con ninguna (re)sacralización de lo político. Las esferas públicas garantizan, no solo

${ }^{84}$ Habermas, J., Faktizität und Geltung. Beiträge zur Diskurstheorie des Rechts und des demokratischen Rechtsstaats, Frankfurt a. M., Suhrkamp, 1992.

85 Cfr. TAYlor, Ch., "Liberal Politics and the Public Sphere», en íd. Philosophical Arguments. Cambridge, Mass./London, England, Harvard University Press,1995, pp. 257-288. Se cita p. 264.

86 Dahrendorf, R., The modern social conflict. An Essay on The Politics of Liberty, Los Angeles, University of California Press, 1990, pp. 70-71.

87 Gerhardt, V., Öffentlichkeit, o. c., pp. 310-311.

88 Ibíd., pp. 46; 306-308.

89 Ibíd., pp. 308-309, 325-329.

$90 \quad$ Ibíd., p. 326.

91 InNerarity, D., «La política después de la indignación», Claves de Razón Práctica, 218 (2011), pp. 30-42; disponible en: http://www.danielinnerarity.es/articulos ; se cita p. 21.

92 Rödel, U.; Frankenberg, G. y Dubiel, H., Die demokratische Frage, Frankfurt a. M., Suhrkamp, 1989. 
«una intersubjetividad no menoscabada» dicho a la habermasiana, sino también, y sobre todo, la posibilidad de contacto personal de cada miembro de la ciudadanía con una "realidad no menoscabada», que no puede ser directamente determinada ni por la vía del saber ni por la del querer. Pues lo que constituye la vida de las sociedades es, dicho ahora con Domingo Blanco a la merleaupontyana, el continuo entrecruzarse de una irreductible multiplicidad y pluralidad de visiones, de actos, de voliciones ${ }^{93}$. Así que tampoco cabe absolutizar la crítica por sí misma. Su sentido es la formación de un juicio suficientemente informado sobre la realidad vivida, que es siempre relación con el mundo en la interacción y nunca se deja reducir a presuntos hechos meramente dados, o ya para siempre interpretados.

Los espacios abiertos de libre expresión, de búsqueda en común, de posibilidad de cuestionamiento constante, de mediación entre política y mundo de la vida, en suma, las esferas públicas, son imprescindibles. Y tiene pleno sentido que sean ámbitos sociales, civiles, de ejercicio de la ciudadanía, con irrenunciable derecho -y deber- de ser críticos. Pues crítica no significa negación, huida, rechazo o destrucción de la política, sino precisamente posibilidad de una renovación y recreación constantes de lo político. Por eso, la «nueva política» que en el crítico año de 1914 propugnan el autor de las Meditaciones del Quijote y la Liga de Educación Política Española, se quiere distinguir de la «vieja» antes que nada «en ser para ella casi lo menos importante la captación del gobierno de España, y ser, en cambio, lo único importante el aumento y fomento de la vitalidad de España». Si hubiera que elegir entre Estado y sociedad, y ocasiones (crisis) se presentarán que lo exijan, la nueva política —afirman- optará por «servir a la sociedad frente al Estado», sobre todo si el Estado es mero "caparazón jurídico» y «formalismo externo» ${ }^{94}$. Además, como "[e]n las épocas de crisis, la verdadera opinión pública no es la expresada por los tópicos al uso», [...] será la nueva política «nueva declaración y voluntad de pensamientos, que, más o menos claros, se encuentran ya viviendo en las conciencias de nuestros ciudadanos» ${ }^{95}$. De ahí que se necesite un nuevo tipo de «verdadero político» al que correspondería justo el papel de remitir a esa «realidad no menoscabada» a que arriba se ha aludido: descubrir, por debajo de los «tópicos ambientes y sin virtud», "aquella realidad de subsuelo que viene a constituir, en cada instante, la opinión verdadera e íntima de una parte de la sociedad», y "penetrando en el fondo del alma colectiva, tratar de sacar a luz en fórmulas claras, evidentes, esas opiniones inexpresas, íntimas de un grupo social, de una generación, por ejemplo» ${ }^{96}$. Cabe añadir que igualmente se necesita hoy —desde las crisis de la política en la era de la inmediatez de las redes sociales digitales-un nuevo tipo de ciudadanía, que antes que romper la saludable tensión entre las instituciones políticas y «la calle» en la dirección de una quimérica «utopía de la des-intermediación», afronte la política asumiendo las paradojas de la autodeterminación democrática, con la capacidad de comprender la complejidad del mundo, los alcances y las limitaciones del ser político de los humanos, con las dificultades que todo ello apareja ${ }^{97}$.

93 Blanco Fernández, D., Principios de Filosofía política. Madrid, Síntesis, 2000, pp. 246-247.

94 ORtega, o. C., pp. 716-718.

95 Ibíd., p. 710.

96 Ibíd., p. 711.

97 INNERARITY, D., «La política después de la indignación», art. cit. 
En las actuales condiciones de reconfiguración de las esferas públicas por la tecnología digital se abre, pues, un horizonte crítico. Los fenómenos referidos y analizados más arriba ejemplifican esta ambivalencia. Las nuevas dinámicas de participación, que oscilan entre importantes movilizaciones que coordinan la presencia en calles y plazas con la interconexión a través de los foros y redes sociales de Internet, y el apoyo relativamente cómodo en favor de una determinada causa mediante un simple clic (slackativism); las nuevas formas de "dialéctica» entre secreto y publicidad en los entornos digitales, con situaciones tan dispares como la vigilancia masiva de algunos Estados y el control de determinadas empresas sobre los flujos de comunicación de la población, las filtraciones y denuncias vía telemática de esas mismas prácticas, el uso del anonimato de la red para fines criminales y terroristas, los esfuerzos de determinados gobiernos por controlar el acceso de sus habitantes a los canales de comunicación electrónica. Son solo algunos signos de la encrucijada en que se hallan las esferas públicas en la era de internet, un futuro justificadamente incierto, en tanto abierto a la crítica y a la acción. Justo las condiciones en que se creería avizorar, como nunca antes en la historia, la ocasión de realizar el ideal cosmopolita kantiano de una ciudadanía mundial, a través una esfera pública de dimensiones planetarias ${ }^{98}$. Precisamente, la expresión más ajustada de la publicidad (Publizität), como principio jurídicopolítico y no solo ético o moral, que negativamente garantiza unas mínimas justicia y conformidad con el derecho, de las acciones políticas y afirmativamente permite que la política desempeñe su tarea de conseguir los fines generales del público en concordancia con el derecho, se encuentra en el Apéndice II del escrito de I. Kant Hacia la paz perpetua. Un esbozo filosófico (1795). La crítica, su posibilidad y necesidad, desempeña una función fundamental en este concepto de lo político centrado en la esfera pública (Öffentlichkeit) como idea y como institución, tendencialmente cosmopolita, que articula Kant en este escrito, pues constituye el medio en y por el que seres capaces y deseosos de autodeterminación pueden encontrar, en la confrontación de las opiniones o representaciones propias de sus necesidades e intereses, una concordancia razonable en sus fines ${ }^{99}$. Posibilidad, sin duda, problemática, pero, en suma, de nuevo estamos ni más ni menos que ante la reinvención, o el (re)descubrimiento, de la política.

Universidad de Almería

José María Muñoz TerróN

jmterron@ual.es

[Artículo aprobado para publicación en diciembre de 2016]

98 Gerhardt, V., Öffentlichkeit, o. c., pp. 248-251.

99 Cfr. Gerhardt, V., Immanuel Kants Entwurf "Zum ewigen Frieden». Eine Theorie der Politik. Wissenschaftliche Buchgesellschaft, Darmstadt, 1995, pp. 101, 186-211. La propuesta de añadir a las dos formulaciones arriba aludidas, negativa y positiva, del principio kantiano de publicidad, una tercera referida a la «eliminación de la desconfianza» del público respecto a las máximas que rigen la actividad de los políticos, incide igualmente sobre la fundamental importancia de la posibilidad de examen crítico para la generación de confianza: GARcíaMarzá, D., "Kant's Principle of Publicity. The Intrinsec Relationship between the two Formulations», en: Kant-Studien, 103 (2012), pp. 96-113. 